\title{
Sanayide Enerji Yönetimi Sistemi için Bir Gıda Tesisinin Enerji Verimliliğinin İyileştirilmesi
}

\author{
Mehmet Bahattin Kıyılmaz ${ }^{1,2}$, Ali Keçebaş ${ }^{3}$, Mustafa Ertürk ${ }^{4 *}$ \\ ${ }^{I}$ Muğla Sitkı Koçman Üniversitesi, Fen Bilimleri Enstitüsü, Enerji Sistemleri Mühendisliği, Muğla, Türkiye \\ ${ }^{2}$ VAT Enerji Hizmetleri Sanayi ve Ticaret AŞ, Üsküdar, İstanbul, Türkiye \\ ${ }^{3}$ Muğla Sttkı Koçman Üniversitesi, Teknoloji Fakültesi, Enerji Sistemleri Mühendisliği, Muğla, Türkiye \\ ${ }^{4}$ Sakarya Uygulamalı Bilimler Üniversitesi, Teknoloji Fakültesi, Makine Mühendisliği Bölümü, Sakarya, Türkiye

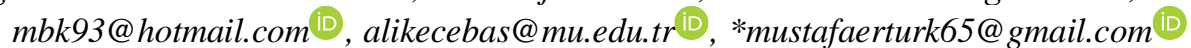 \\ Makale gönderme tarihi: 23.10.2020, Makale kabul tarihi: 09.02.2021
}

\begin{abstract}
$\ddot{O} z$
Geçen on yılda ISO 50001 Enerji Yönetim Sistemi (EnYS) enerji kuruluşların enerji performansını arttırma

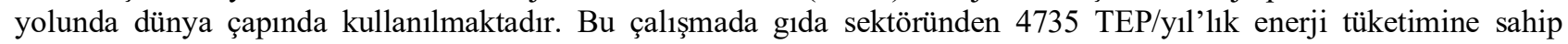
dondurma üretimi yapan büyük ölçekli bir tesise bu sistem uygulanmıştır. Böylece EnYS etüdü ile tesisteki enerji verimliliği, enerji kullanımı ve tüketiminde mevcut durum tespit edilmiştir. Sonra enerji tasarrufu konusunda verimlilik arttırıcı uygulama ve projeler ile birlikte alınacak önlemler araştırılmıştır. Çalışma sonuçları kısa vadede üç alanda iyileştirme yapılması gerektiğini önermiştir. Bu alanlar ise buhar hatlarındaki kaçaklar ile basınçlı hava dağıtımındaki izlenen yanlış stratejiler ve dengesiz olarak yüklenen transformatörlerdir. 2019 yılı için tesiste yapılacak basit müdahale ve alınacak tedbirler ile yıllık $929555 \mathrm{kWh}$ enerji ile $371822 \mathrm{TL}$ ekonomik değer elde edilebilir. Ayrıca bu tasarrufa karşılık $1200733 \mathrm{~kg} \mathrm{CO}$ salınımının önüne geçilebilir.
\end{abstract}

Anahtar Kelimeler: Enerji yönetimi, enerji yönetim sistemi, enerji verimliliği, gıda tesisi örneği

\section{Improving the Energy Efficiency of a Food Plant for an Energy Management System in Industry}

\begin{abstract}
In the last decade, ISO 50001 Energy Management System (EnMS) has been used worldwide to increase the energy performance of energy organizations. In this study, the system was applied to a large-scale facility producing ice cream with an energy consumption of 4735 TEP per year from the food industry. Thus, the current situation in energy efficiency, energy use and consumption at the facility was determined through an EnMS survey. Then, the measures to be taken together with the practices and projects to increase efficiency in energy saving were investigated. The results of the study suggested that improvements should be made in three areas in the short term. These areas are leaks in the steam lines, wrong strategies followed in compressed air distribution and unbalanced transformers. With the simple intervention and measures to be taken at the facility for 2019, an economic value of $371822 \mathrm{TL}$ can be obtained with $929555 \mathrm{kWh}$ of energy per year. In addition, $1200733 \mathrm{~kg}$ of $\mathrm{CO}_{2}$ emission can be prevented against this saving.
\end{abstract}

Keywords: Energy management, energy management system, energy efficiency, food facility example

\section{GİRIŞ}

Ülkelerin gelişmişlik düzeylerinin bir ölçüsü de enerji üzerinden yapılmaktadır. Bu bağlamda kişi başına tüketilen enerji miktarı ve enerji yoğunluğu gibi göstergeler kullanılmaktadır. Kişi başına tüketilen enerjinin yüksek olması ülkenin ekonomik faaliyetlerinin canlı ve refah düzeyinin yüksek olduğunu göstermektedir. Enerji yoğunluğunun yüksek olması ise enerji verimsiz üretim yapıldığını, birim ürün veya hizmet başına yüksek miktarda enerji harcandığı anlamına gelmektedir.

Giderek artan enerji fiyatları, enerji arzındaki güvensizlikler, teknolojik gelişmeler, küresel ısınma gibi çevresel sorunlar, geleneksel kaynakların hızla tüketilmesi ve daha fazla enerji bağımsızlığ eğilimleri, mevcut enerji potansiyelinin daha verimli etkin kullanmasına ve yönetmeye itmiştir (Aksoy ve 
ark., 2013).

Faaliyet alanı ne olursa olsun ulusal ve uluslararası rekabette yer edinebilmek için kuruluşlarında enerji girdi maliyetlerinin azaltılarak enerji verimliliğine gereken önemi vermesi şarttır. Özellikle enerji tüketimi fazla ve enerji yoğun sektörlerde birçok noktada göz ardı edilen enerji verimliliği potansiyelleri mevcuttur (Ural ve ark, 2020). Bu potansiyellerin ortaya çıarılması hem işletmenin hem de ülke ekonomisinin yararına olacaktır. Enerjinin verimli kullanımını ve sistematik olarak enerji yönetimi ile sera gazı emisyonlarında azalma ve enerji maliyetlerinin azaltılmasını sağlayan ISO 50001 Enerji Yönetim Sistemi (EnYS) dünyada birçok yerde uygulanmaktadır. ISO 50001 standardıyla tanımlanan enerji yönetimi, genel olarak enerji verimliliği, kullanımı ve tüketimi ile ilgili ölçülebilir sonuçlar olarak tanımlanan enerji performansının sürekli iyileştirilmesine odaklanır. ISO 50001 standard1, ABD ANSI/MSE 2000: 2008 ve Avrupa Birliği EN 16001: 2009 gibi mevcut ulusal standartlar üzerine inşa edilmiştir (Ferland ve ark., 2009). Danimarka'da yapılan enerji yönetiminin uygulanmasına ilişkin bir araştırmada kuruluşların yalnızca \%3-14'ünün enerji yönetimi uyguladığını göstermiştir. İsveç'te \%25-40 iken Türkiye'de \%22'dir (Christoffersen ve ark., 2016). Dolayısıyla ülkelerde enerji verimliliği teşvik ve desteklerinden yararlanılması için bu sistemin kurulması şartlar arasındadır. EnYS, endüstriyel şirketlere veya üretim tesislerine, yani çıtı bir ürün veya maldan oluşan kuruluşlara daha kolay aktarılabilir. Literatürde çimento (Pelser ve ark., 2018), inşaat (Fichera ve ark., 2020), 1sitma sistemleri (Mendoza ve ark., 2019) gibi uygulamalarda görülmektedir.

Enerji verimliliği, sürdürülebilir kalkınma ve rekabetçiliğin en önemli bileşenidir. Küresel, ulusal ve bölgesel düzeyde büyük önem taşımaktadır. Artan enerji fiyatları, enerji arz güvenliği ile ilgili endişeler, teknolojik gelişmeler, iklim değişikliği ve daha fazla enerji bağımsızlığı eğilimleri, enerji verimliliği konusundaki çalışmaların ana nedenleridir (Uzun ve Değirmen, 2018). Ülkelerin gelişmişlik düzeylerinin bir ölçüsü de enerji üzerinden yapılmaktadır. Bu bağlamda kişi başına tüketilen enerji miktarı ve enerji yoğunluğu gibi göstergeler kullanılmaktadır. Kişi başına tüketilen enerjinin yüksek olması ülkenin ekonomik faaliyetlerinin canlı ve refah düzeyinin yüksek olduğunu göstermektedir. Enerji yoğunluğunun yüksek olması ise enerji verimsiz üretim yapıldığını, birim ürün veya hizmet başına yüksek miktarda enerji harcandığ 1 anlamına gelmektedir.

Enerji verimliliği tanım olarak, binalarda yaşam standard1 ve hizmet kalitesi, sanayi işletmelerinde üretim kalitesi ve miktarında düşüşe neden olmadan birim hizmet veya ürün miktarı başına enerji tüketiminin azaltılmasını sağlayan bir uygulamadır (EMO, 2011). Enerji tüketiminin, dönüşümünün, aktarımının yüksek olduğu tesislerin işletilmesinde veya yeni tesislerin kurulumunda modernizasyon ve kapasite arttırma çalışmalarında, enerji verimliliğine yönelik potansiyeller araştırılarak etüt ve proje çalışmalarında önlemler ve uygulamalar dikkate alınmalıdır.

Enerji yönetiminin amac1, enerjinin daha etkin ve verimli kullanılması ile işletmenin kazancını arttırmaktır. Bunun için yapılması gereken ilk iş enerji tasarrufu ve verimlilik imkânlarının ortaya çıkarılması için bilgi toplama, ölçüm, izleme ve değerlendirme yapılmasıdır. Söz konusu imkânların takibi, değerlendirilmesi içinde bir takım enerji performans göstergelerine (EnPG) ihtiyaç duyulur. Enerji performans1, enerji verimliliği, enerji kullanımı ve enerji tüketimi ile ilgili ölçülebilir sonuçlardır. Kuruluş tarafından tanımlanan enerji performansının nicel değeri veya ölçüsü, performans göstergeleri olarak tanımlanır. EnPG'lere birim zamandaki enerji tüketimi, birim üretim bașına enerji tüketimi veya üretime has özellikler dikkate alınarak çok değişkenli farklı modeller örnek verilebilir.

Üretimden tüketime her aşamada enerjinin etkin kullanılması, israfin önlenmesi, enerji maliyetlerinin ekonomi üzerindeki yükünün hafifletilmesi ve çevrenin korunması için enerji kaynaklarının ve enerjinin kullanımında verimliliğin artırılması amacını taşıyan 18/04/2007 tarih ve 5627 say1lı, "Enerji Verimliliği Kanunu" ülkemize, gelişmiş ülkelerdeki standartlarda önemli yenilikler getirmiştir (Halkbank, 2007). Enerji verimliliği çalışmalarının ülke genelinde tüm ilgili kuruluşlar nezdinde etkin olarak yürütülmesi, sonuçlarının izlenmesi ve koordinasyonu amaciyla Enerji Verimliliği Koordinasyon Kurulu (EVKK) oluşturulmuştur (Uzun ve Değirmen, 2018). Pekaçar (2011) enerji tüketimini yönetmek ve azaltmak için 
en iyi uygulama rehberi olarak ISO 50001 EnYS'yi kullanılmasını tavsiye etmektedir. Mevcut yasalarımızda da belli bir değerin üzerinde enerji tüketimi olan işletmeler enerji verimliliği destek ve teşviklerinden yararlanabilmek için enerji yönetim sistemi kurulması ve enerji verimliliği konularında çalışmalar yürütecek enerji yöneticisi sertifikasına sahip teknik insanların çalıştırılması zorunludur. Özellikle enerji yoğunluğu yüksek sanayi kuruluşlarında; enerji tüketimi yüksek; motorlar, fanlar, buhar ve basınçlı hava sistemleri, kazanlar, elektrik dağıtım sistemleri, yalıtım, pompa sistemleri gibi noktalarda yapılabilecek birçok enerji verimliliği uygulamalan mevcuttur. Uzun ve Değirmen (2018) endüstriyel işletmelerde enerji verimliliğini arttırılması yönünde uygulanan enerji yönetimi sistemlerini, enerji etütlerini ve pinch analizini ele almıștır. Özellikle ISO 50001: Enerji Yönetim Sistemi ve araçları ile yıllık enerji maliyetleri $\% 5$ ile $\% 20$ arasında düşebileceğini rapor etti. Paker (2019) bir otomotiv sektörü için ürün bazındaki özgül enerji tüketimleri izlenmesi ile enerji verimliliği ve risk analizi yapmıştır. Böylece ISO 50001'in faydalı olduğunu ve özgün enerji tüketimini azaltan enerji risk analizi ve yönetim süreç adımlarını tablo olarak hazırlamıștır.

Enerji verimliliği politikalarının uygulanmasıyla birlikte Avrupa Birliği tarafindan son zamanlarda en fazla enerji yoğunluğuna sahip sektörün gida endüstrisi olduğu rapor edilmiştir. $\mathrm{Bu}$ k1smen, üretim hacimleri ve kalite, hijyen ve gida güvenliği standartlarının zorunlu kıldığ 1 gereksinimler tarafından yönlendirilen soğutma sistemlerinin artan enerji tüketiminden kaynaklanır (Polat ve ark., 2017). Mezinska and Strode (2015) gıda sektörü şirketlerinde ortaya çıkan çevre yönetimi konusunda yaşam döngüsü yaklaşımını kullanarak çevre boyutlarını belirlemiş ve çevre üzerindeki etkilerini değerlendirmiştir. Corsini ve ark. (2016) EnYS içinde sistemlerin, süreçlerin ve ekipmanların enerji performansının izlenmesi amacıyla çok değişkenli bir enerji gösterge performansını tanıtmış ve gida endüstrisindeki amonyak soğutucular için değerlendirmiştir. Jovanovic ve ark. (2017) Sırbistan'ın gıda işleme ve metal olmayan mineral ürünlerin imalatlarında ISO 50001 EnYS'nin P-U-K-Ö (planla, uygula, kontrol et, önlem al) döngüsü uygulamasını gerçekleştirdi. Ruşen ve Çevik (2020) Karaman'da bir gıda işletmesine ait gofret üretim hattının enerji verimliliğini değerlendirmişlerdir. Kazan sistemlerinde brülör üzerindeki öneriler ile kazan verimi \%5,2'lik bir artış ve böylece reküparatör kullanımı, 1S1 kayıp ve kaçaklarının önlenmesi işletmede y1llık 3391,9 \$ kazanç olacağını öngörmüşlerdir. Brülörde $\mathrm{O}_{2}$ 'nin düzenli kontrolü ile 5998,85 \$ değerinde yakıt tasarrufu belirlemişlerdir.

Yukarıda bahsedilen literatür gözden geçirildiğinde bir ürün veya mal çıktısı olan sektörlerdeki kuruluşlara ISO 50001 EnYS'nin kullanılmasının faydalı olduğunu göstermektedir. Böylece kuruluşlarda enerji verimliliği ve yakıt tasarrufunun artışının ve dolayısıyla çevresel etkilerin azaldığı görülmektedir. $\mathrm{Bu}$ çalıșma yukarıda sunulan literatür ve yazarların bilgisi dahilinde ISO 50001 EnYS'ni ilk kez gerçek bir uygulama olarak gıda sektöründeki dondurma üretim tesisine uygulanmıştır. Dondurma ürünlerin imalatlarında P-U-K-Ö (planla, uygula, kontrol et, önlem al) döngüsü uygulaması gerçekleştirilir. Böylece tesisin enerji tasarrufu konusunda verimlilik arttırıci uygulama ve projeler ile birlikte alınacak önlemler belirlenmiştir.

\section{ENERJI YÖNETIMMI}

Enerji verimliliği çalışmalarının odak noktası enerji yönetimidir. Enerji yönetimi, enerji kaynaklarının ve enerjinin verimli kullanılmasını sağlamak için yürütülen eğitim, etüt, ölçüm, izleme, planlama ve uygulama faaliyetleriyle ilgilidir (EMO, 2011). Diğer yönetim faaliyetlerine benzer şekilde enerji yönetimi; planlama, koordinasyon ve kontrol mekanizmaları birbirlerinden bağımsız olur ise etkisiz kalacak olan işlevler bir araya gelerek bir bütün oluşturur. Enerji Yönetimi, ürün kalitesinden, güvenliğinden veya tüm çevre koşullarından ödün vermeden ve üretimi düşürmeden enerji kaynaklarının ve enerjinin daha verimli ve akılcı kullanımı doğrultusunda yapılandırılmış ve organize edilmiş disiplinli bir iştir. Enerji yönetimi çalışmaları ile yürütülen verimlilik arttırıcı proje ve uygulamalar ile görülmüştür ki belli bir programa bağlı olmadan atılacak basit adımlarla, enerji verimliliğinde, $\% 5$ ile $\% 15$ arasında geri dönüşler ve iyileşmeler sağlanabilir (Kaya ve Öztürk, 2014).

Enerji yönetimi, enerji verimliliği iyileştirilmelerinin yanında yapılacak etütler ile enerji kullanılan bölümlerin izleme, ölçme, analiz 
faaliyetleri ile ekipmanların incelenmesi sonucunda da maliyetlerin azaltılması olanakları değerlendirilir. Toplam verimli bakım, otonom bakımı öngörerek arızanın oluşmadan önleme yaklaşımı ile kayıplar azaltılarak verimliliğin arttırılmasında uygulanan bir yöntemdir. Enerji yönetimi ile ilgili faaliyetlere başlanırken iki husus önemlidir. Bunların ilki üst yönetimin katkı ve desteği, ikincisi enerji yönetim ekibinin oluşturulmasıdır. Eğer şirket üst düzey yetkilileri bu konuda gerekli önemi ve özeni göstermez ise alt kademelerin yapacağı çalışmalar ve çabaların bir önemi kalmaz. İkinci önemli nokta, bu desteğin göstergesi olarak programı yürütecek enerji yönetim ekibinin oluşturulmasıdır.

ISO 50001 Enerji Yönetim Sistemi (EnYS) Standard 1 enerjinin verimli kullanılması, enerji israfının önlenmesi, enerji maliyetlerinin ekonomi üzerindeki yükünün azaltılması ve çevrenin korunması için enerji kaynakları ve enerji kullanımında verimliliğin artırılmasına ilişkin usul ve esasları düzenler. $\mathrm{Bu}$ standart, enerjinin sistematik yönetimi vasıtasıyla sera gazı emisyonlarının, çevresel etkilerin, enerji maliyetlerinin azaltılmasına yol açmayı amaçlamaktadır (ETKB YEGM, 2013). ISO 50001 EnYS modeli Şekil 1'de sunulan planla, uygula, kontrol et, önlem al (P-U-K-Ö döngüsü) olarak gösterilen döngü, sürekli iyileştirme çerçevesine dayalıdır ve enerji yönetimini kuruluşların günlük rutin uygulamalarının içine alır.



Şekil 1. ISO 50001 EnYS modeli için PUKÖ döngüsü

Şekil 1'de planlama, enerji yönetimi programının en önemli bileşenidir. Temelde iki işlevi vardır. Birincisi, iyi bir planlama ile enerji arzı noktasında yaşanan sorunlardan kuruluş/firma korunur. İkincisi ise olaylar yıl içinde planlama yapılarak enerji yönetimi programına sürekli vurgu yapılması ve programın aktif, işletilebilir kalması sağlanır. Uygulama ve işletimde, planlama sürecinde elde edilen eylem planları ve diğer çıtılar uygulanır. Önemli enerji kullanımları ile ilgili olarak tüm çalışanların bilinç düzeyi arttırılarak, eğitim, beceri ile tecrübelere sahip olması sağlanmalıdır. Kuruluş/firmada, enerji performansını etkileyen ve belirleyen faaliyetlerin temel karakteristiklerinin belirli aralıklarla izlenilmesi, ölçülmesi ve analiz edilmesi sağlanmalıdır. Önlem al aşamasında ise kuruluş/firma yönetimi enerji yönetimini; uygunluk, yeterlilik ve etkinliğinin sürekliliğini güvence altına almak için planlanmış aralıklarla gözden geçirmelidir.

Enerji etütleri, enerji verimliliğini artırma olasılıklarını ortaya çıkarmak için yapılan ve bilgi toplama, ölçme, değerlendirme ve raporlama aşamalarını içeren çalışmalardır ve bina veya tesislere uygun ekipmanlarla çeşitli tekniklerle çeşitli ölçümler yapılır. Etüt sonucunda tesisin veya binanın enerji tüketimi, kullanımı konusunda ne durumda olduğu belirlenir ve enerji tasarruf firsatları buna göre değerlendirilir (EMO, 2011). Ayrıca enerji etüdü ile enerji tasarrufu potansiyelleri yanı sıra enerji atıklarının ve sera gazı salınımlarının belirlenerek bunlarla ilgili geri kazanımı sağlayacak veya önleyecek tedbirler ile teknik ve ekonomik boyutların ortaya konulması amaçlanır (Söğüt ve ark., 2013).

İki aşamadan oluşan ön etüt ile ilk olarak, tesiste yapılması planlanan yatırım kararları ile mevcut durumda enerji yönetimi konusunda yapılanlar hakkında bilgi sahibi olunur. İkinci aşama enerji verimliliği çalışmalarının yapılacağı sistem ve ekipmanların çalışmasının gözden geçirilmesi amacıyla teknik bir çalışma yapılmasıdır. Detaylı olmayan bu teknik çalışma ile genel olarak kuruluş, etüdü yapacak kişiler tarafindan gezilerek; devre dış1, verimsiz olan ekipmanlar belirlenerek, enerjinin boşa harcandığı noktalar, örneğin: kötü yalıtım, buhar ve basınçlı hava kaçakları vb. durumlar ile enerji geri kazanma potansiyelleri tahmin edilir. Enerji tüketen tüm ekipmanların profili çıkarılır ve özellikleri belirlenir. Enerji yönetimi konusunda 
gözlenen uygunsuzluklar belirlenerek, öneriler getirilir.

Ön etüt ile elde edilen veriler doğrultusunda detaylı etüt kapsamına alınması uygun görülen alanlarda, enerji transferinin ve dönüşümünün yoğun olduğu, yoğun enerji tüketen (kazan, firın gibi) ekipman, teçhizat ve bölümlerde işletmenin gerçek çalışma koşullarında ölçüm cihazları ile belirli periyotlar ile ölçüm ve hesaplamalar yapılır. İyileștirilmesi gerekli görülen noktalarda önleme ve enerji geri kazanma potansiyelleri tahmin edilir. $\mathrm{Bu}$ bakımdan ön etüt çalışmalarına göre daha uzun ve detaylı yapılan çalışmalardır. Detaylı enerji etüdü, konu hakkında eğitim almış, yeterli bilgi ve donanıma sahip bir ekip tarafindan yapılması gerekir.

Çizelge 1. Etüt çalışmasında kullanılan cihazlar ve alınan ölçümler

\begin{tabular}{|c|c|c|c|c|c|}
\hline & & & alibrasyon B & ileri & \\
\hline Cihaz adı & Seri No & Tarihi & $\begin{array}{c}\text { Geçerlilik } \\
\text { süresi }\end{array}$ & $\begin{array}{c}\text { Yapan } \\
\text { kurum/kuruluș }\end{array}$ & $\begin{array}{c}\text { Etüt sirasında } \\
\text { kullanıldığı yerler }\end{array}$ \\
\hline Enerji analizörü & PX50A106 & 22.02 .2018 & 22.02 .2019 & SİMKAL & Tüm tesiste \\
\hline Termal kamera & T197063 & 11.052018 & 11.05 .2019 & FLİR & Tüm tesiste \\
\hline Akış ölçer & 24912 & - & - & & Su ve kondens \\
\hline Lüksmetre & Q563817 & 27.05 .2018 & - & METKAL & Tüm tesiste \\
\hline Anemometre & Q561958 & 02.06.2018 & - & METKAL & $\begin{array}{c}\text { Evaporatör ve } \\
\text { kondenserlerde }\end{array}$ \\
\hline Sicaklık ölçer & 06127095 & 09.10 .2018 & 09.10 .2019 & METKAL & Tüm tesiste \\
\hline Trapman & BUJ010 & & & & Kondenstoplarda \\
\hline Baca gazı analizörü & 2415 & 30.03 .2018 & 30.03 .2019 & RAM & - \\
\hline
\end{tabular}

\section{SANAYIDE ENERJI YÖNETIMI} UYGULAMASI

$\mathrm{Bu}$ çalışmada gıda sektöründe faaliyet gösteren bir dondurma ürün tesisinde yapılacak yatırımlar ve mevcut durumda enerji tüketimi ile enerji maliyetlerinin oranının belirlenmesi, son iki yıla ait enerji tüketimi değerlerinin tespiti, enerji yönetimi konusunda tesisin bulunduğu nokta ve bu konularda yapılabilecek iyileştirme olanakları için enerji etüdü çalışması yapılmıştır. Ayrıca etüt sonucunda önerilecek verimlilik arttırıcı projeler ele alınacaktır. Uygulamanın kapsamı; (i) buhar ve kondens hatlarının incelenmesi (Papar ve ark., 2017), trafo ölçümleri, proseste termal ölçümler, sıvı akışkanlarda debi ölçümleri, enerji tüketim hesabı, enerji maliyet hesabı ve önemli enerji tüketim ve kayıp noktaları olacaktır. Ayrıca Çizelge 1'de etüt çalışmasında kullanılan cihazlar ve alınan ölçümleri listelenmiştir.

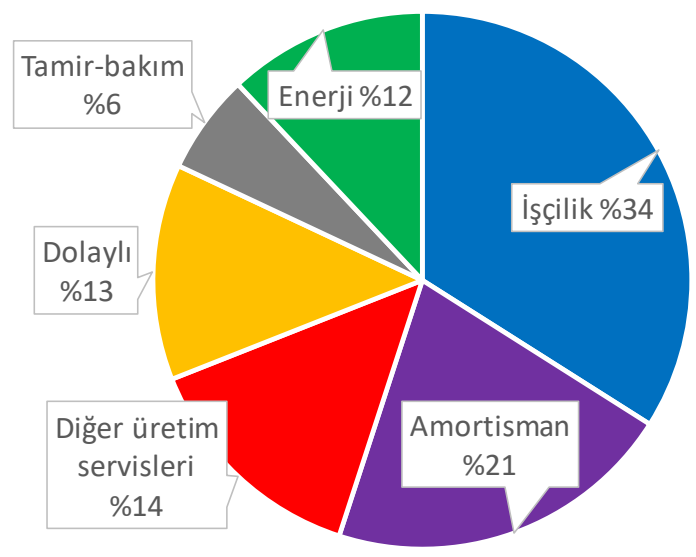

Şekil 2. Tesiste gerçekleşen maliyetlerin dağılımı

Çizelge 2. Tesisin enerji tüketim kaynaklarının ve maliyetlerinin dă̆ılımı

\begin{tabular}{|c|c|c|c|c|c|}
\hline & \multicolumn{3}{|c|}{ Tüketim } & Maliyet dağılımı \\
\hline Enerji türü & Miktar & Birim & Ton Eşdeğer Petrol (TEP) & \% Toplam & \% Toplam \\
\hline Elektrik & 32773637 & $\mathrm{kWh}$ & 2819 & 60 & 86,4 \\
\hline LNG & 305326 & $\mathrm{~kg}$ & 329 & 7 & 1,2 \\
\hline Buhar & 23793722 & $\mathrm{~kg}$ & 1587 & 33 & 12,4 \\
\hline Toplam & & & 4735 & 100 & 100 \\
\hline
\end{tabular}




\section{Etüt Calıșması}

Ön etüt neticesinde tesisteki gider maliyetlerin dağılımı Şekil 2'de verilmiştir. Şekil 2'de görüldüğü gibi işçilik \%34 ile en yüksek değerdedir. Ancak enerji, tamir bakım ve dolaylı maliyetlerde girdi maliyetlerinde büyük bir yekûn tutmaktadır. Böylece tüketilen enerjinin kaynak cinsine göre yüzde tüketim ve maliyet dağılımları Çizelge 2'de listelenmiştir. Tesiste en fazla \%60 ile elektrik tüketimi ve \%86,4 ile maliyetleri vardır. Sonrasında ise buhar gelmektedir.
2017 ve 2018 y1lına ait yoğunluklu enerji tüketimi (SET) değerleri yıl içindeki aylara göre değişimleri Çizelge 3 'te verilmiştir. Çizelgede 1 . ayın Nisan ayı olduğu ve gida üretimin Ağustos ayında tavan yaptığ 1 görülmektedir. Çizelge 3 'den görüldüğ ü gibi üretilen $\mathrm{kg}$ başına gıda ürünü için 2017 yılında $321 \mathrm{kcal}$ enerji tüketirken 2018 yılında 279 kcal olarak bir düşüş oluştur. Burada 10. ve 11. aylarda üretim değerlerinin olmaması sebep olmuştur.

Çizelge 3. 2017 ve 2018 yıllarına ait SET değerlerinin bir karşılaştırılması

\begin{tabular}{|l|r|r|r|r|r|r|}
\hline \multirow{2}{*}{ Ay Yıl } & \multicolumn{2}{|c|}{ Enerji tüketimi (kcal) } & \multicolumn{2}{c|}{ Üretim (kg) } & \multicolumn{2}{c|}{ SET (kcal/kg-ürün) } \\
\cline { 2 - 7 } & $\mathbf{2 0 1 7}$ & $\mathbf{2 0 1 8}$ & $\mathbf{2 0 1 7}$ & $\mathbf{2 0 1 8}$ & $\mathbf{2 0 1 7}$ & $\mathbf{2 0 1 8}$ \\
\hline 1 & 4083555910 & 3114033867 & 11355000 & 8022000 & 360 & 388 \\
\hline 2 & 4131237395 & 3683016226 & 14010000 & 11951000 & 295 & 308 \\
\hline 3 & 5071301170 & 5047287240 & 17910000 & 19349000 & 283 & 261 \\
\hline 4 & 4779672700 & 5323345207 & 18995000 & 21214000 & 252 & 251 \\
\hline 5 & 4790425700 & 5256978996 & 17128000 & 23111000 & 280 & 227 \\
\hline 6 & 4748831980 & 5391189583 & 14620000 & 22687000 & 325 & 238 \\
\hline 7 & 3827929760 & 5091068700 & 13108000 & 20326000 & 292 & 250 \\
\hline 8 & 2497647350 & 4317836990 & 6417000 & 15044000 & 389 & 287 \\
\hline 9 & 321092389 & 2759918010 & 0 & 7298000 & 0 & 378 \\
\hline 10 & 567142795 & 457892953 & 0 & 0 & 0 & 0 \\
\hline 11 & 306692261 & 756001420 & 0 & 0 & 0 & 0 \\
\hline 12 & 1612132490 & 2864794586 & 7730000 & 8746000 & 209 & 328 \\
\hline Toplam & 36737661040 & 44063363778 & 114317000 & 157750000 & 321 & 279 \\
\hline
\end{tabular}

\section{Üretim üniteleri ve sürec bilgileri}

Karıșım Bölümü: İlk malzemelerle istenilen formülasyonu ve formülasyondan gelen tarife göre hesaplama yapılır, maddeler tartılır ve seçilen malzemelerle birlikte "dondurma karışımı" olarak bilinen ürünü üretmek için harmanlanmış karışım seçilir. Harmanlamada tozları dâhil etmek için hızlı çırpıntı gerektirir ve burada genellikle yüksek hızlı karıştırıcılar kullanılır.

Pastörizer 1-2-3 Bölümü: Karışım bölümünden sonra dondurma, pastörize edilir. Pastörizasyon patojenik bakterilerin yok edilmesi için tasarlanan sistemdir. Biyolojik kontrol noktasıdır. Çok önemli olan bu işleve ek olarak, pastörizasyon da "psychrotrophs" gibi bozulmalar organizma sayisinı azaltır ve bileşenleri bazı hidratlara yardımcı olur (proteinler, stabilizatörler).

Sos Hazırlama Bölümü: Tankların içinde serpantin vardır. İçinde sıcak su dolaşımıyla hazırlanan dondurma sosu 1sitilır.

Geri Dönüşüm Bölümü: Geri dönüşüm bölümüdür. Diğer bölümlerden gelen atıklar, burada eritilir ve üretime tekrar geri gönderilir.

CIP Odası: Burada, karışım ceket suyu tank1, kuvertür ceket suyu tank1, yer yıkama suyu tank1, yer yıkama suyu tank1, konsantre deterjan tank1 ve 2 adet soğuk su tankı bulunmaktadır.

Dondurucular: Dondurma dinleme bölümünden buraya gelmektedir. Dondurma kalıplara doldurulur ve kalıplarda 3 bar basınçta buhar ile MS-4 (5 adet) kalıp içerisinden dondurma çıkarılır. Kullanılan buhar dondurmaya temas etmez. $\mathrm{Bu}$ ünite dondurmanın şekillendirildiği ünitedir.

Külah Bölümü: Külahın hazırlandığı bölümdür.

Dinlendirme Bölümü: Yapılan ara ürünlerin +4 ${ }^{\circ} \mathrm{C}$ 'de dinlendirildiği bölümdür.

Sertleştirme Tünel: Bazı parçacıklar eklendikten sonra, paketlenmiş olan dondurmada 
kalan su çoğu donmuş olan $-40^{\circ} \mathrm{C}$ ile $-30^{\circ} \mathrm{C}$ 'de bir dondurucuya yerleştirilir. $\quad-25^{\circ} \mathrm{C}$ aşağısında dondurma, buz kristal büyüme tehlikesi olmadan belirsiz süre istikrarlı şekilde sertleştirilir. Buz kristallerinin büyümesini engellemek ve mümkün kristal büyüme oranını durdurmak depolama sıcaklığına bağlıdır.

Yaşlanma Bölümü: Karışım sonrası en az dört saat ve genellikle gece yapılan bir yaşlanma işlemidir. $\mathrm{Bu}$ aşama, proteinler ve polisakkaritlerin tam hidrat hali için ve soğumaya ve kristalize yağ için zaman sağlar

Üretim süreci Şekil 3'te şematik diyagram olarak verilmiştir. Enerji etüdünün yoğunlaşacağ 1 tesise ait yardımc1 üniteler ise 1. buhar sistemi tesisat1, 2. hava kompresörleri, 3. amonyak kompresörleri, 4. elektrik sistemleri, 5. kazan dairesi ve sicak su boylerleri, 6. su aritma tesisi ve 7. aritmadir.

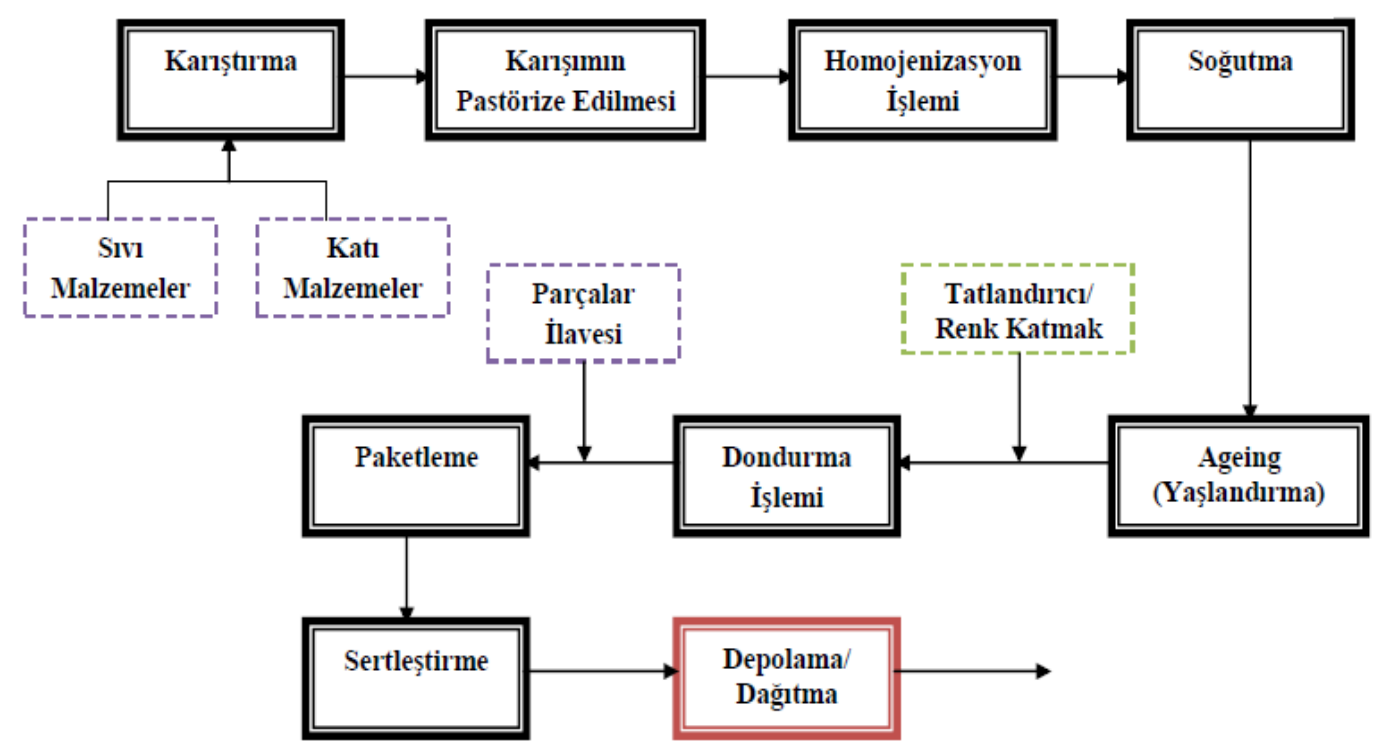

Şekil 3. Üretim prosesi aşamaları

\section{Buhar sistemi}

Tesiste buhar yakındaki bir enerji santralinden satın alınmaktadır. Satın alınan buhar 14 bar ve 200 ${ }^{\circ} \mathrm{C}$ 'de tesise gelmekte, farklı kullanım noktalarına 3 bar ve 5 bar basınçta gönderilmektedir. Buhar ikincil olarak kullanılmakta ve olușan kondens geri dönmektedir. Ria makinaları, Karışım plantin ve bir kısım kullanıcılardan, klima sistemi, idari bina, külah bölümü ve atık arıtma bölgesinden, buhar geri dönüş yapmamaktadır. Ana buhar sayacı her ay sıfirlanarak takip edilmektedir. Etüt sırasında anlık $3629 \mathrm{~kg} / \mathrm{h}$ ve toplam $195404 \mathrm{~kg} /$ gün'dür. Her gün tüketilen miktar toplam tüketilen miktardan çıkarılarak günlük tüketim bulunmaktadır. Buhar kullanım dökümü:

Karışım Bölümü: Buhar burada proses suyunun 1sıtılmasında kullanılıyor ve kullanılan 1sı değiştirici HPW 1sıtma 1sı değiştircisidir.

Pastörizatör 1-2-3: Su ile dondurma isitıliyor.
Burada 2 adet 1 sı değiștirici bulunmaktadır. Buhar 1sıtma amaçlı olarak kullanılıyor. Sistemde mekanik trap bulunmaktadır ve buhar basınc1 3 bardır.

Sos Hazırlama Ünitesi: Sosun 1sitılması için gerekli olan suyun 1sit1lmas1 amaciyla buhar kullanıliyor. Sos tank1 ceketlidir ve 1sitilan sicak su bu ceketin içinden dolaşıyor.

Ön Karışım Tankları: Ünitede 7 adet tank bulunmaktadır. 85 civarındaki 1sıtılmış su ürün hazırlamada kullanılıyor.

Geri Dönüşüm Bölümü: Geri dönüşüm ünitesi. Prosesten gelen ürün tekrar eritiliyor ve sisteme kat1lyor.

Tesisteki klima santralleri ile çeşitli süreçlerde kullanılan buhar yakındaki enerji santralinden satın alınmaktadır. Buhar öncelikle ana kolektöre giriş yapmakta sonrasında da ihtiyaç noktalarına branşmanlar yardımıyla taşınmaktadır. Şekil 4'te buharın tesise giriş yaptığ $\mathrm{k}_{1}$ sım ve dağıtım 
kollektörü görülmektedir.



Şekil 4. Buhar dağıtım sistemi

Yapılan ön etüt ile gerek kolektörün tasarımı gerekse kolektör üzerindeki kondenstopların seçimi doğru olarak yapıldığı görülmüştür. Kollektör üzerindeki her bir vana, boruların yalıtımında kullanılan malzemeyle yalıtılmıştır. Ana kolektör üzerinde bir tane 1 inch şamandıralı kondenstop ve iki tane de $1 / 2$ inch termodinamik kondenstop bulunmaktadır.

Branşmanlar üzerinde yapılan incelemelerde 30 metrede bir konulmas1 gereken önerilen kondens ceplerinin bulunmadığ 1 görülmüştür. Servisler binasından geçen ve yeni çöp binasına kadar buhar taşıyan 300-350 m'lik hattın üzerinde kondens cebi ve kondenstop bulunmamaktadır. Bunun yanında hattın önünden geçtiği binaların 1sıtılması için alınmış branşmanlarının kondens hattı üzerinde termodinamik kondenstop kullanılmıștır. Kullanılan kondenstop tipi doğrudur ancak hem grup kondenstoplama (iki radyatöre bir kondenstop) uygulanmas1 hem de termodinamik kondenstopun korunaksız olarak kullanılması uygun değildir. Özellikle kış aylarında dışarıdaki yağmur, kar ve soğuğa maruz kalan termodinamik kondenstoplar daha sik boşaltma yapmaya başlar ve bu da bir miktar buharında kondens ile birlikte israf olmasına sebep olur.



Şekil 5. Hindistan cevizi yağı depolama ünitesi

Şekil 5'te gösterildiği gibi hindistan cevizi yağının depolandığı tankların ceket araları, içindeki yağın donmaması için açık buharla 1sıtılmaktadır. $\mathrm{Bu}$ işlem donmanın daha çok olduğu kış aylarında yapılsa da önemli miktarda buharın israf olmasına sebebiyet vermektedir. İşlem sırasında sadece buharın dışarı püskürtülmesinden kayıp olmaz. Bunun yanında kondensin de geri döndürülememesi şartlandırılmış kaliteli suyun israfı anlamına gelir.

Buharın tesise girdiği kolektörden kullanıldığ1 son noktaya kadar hiçbir noktada separatör kullanılmadığ1 görülmüştür. Kolektörlerden sonra tesise dağılan branşmanlar üzerinde separatör bulunması buharın kalitesini yükseltmekle kalmaz aynı zamanda basınç düşürücü, kontrol vanası, buhar sayac1 gibi hassas ekipmanların kullanım ömürlerinin uzamasını sağlar.

Klima santrallerine beslenen buharın bir separatörden geçirilerek verilmesi klimanın değişken yüklere verdiği reaksiyon süresini kısaltır. Çünkü kuruluk derecesi \%90 olan buhar ile \%100 kuruluk derecesine sahip buharın kalorifik değeri aynı değildir.

Tesisatta hat sonlarında hava atıc1 kullanılmalıdır. $\mathrm{Bu}$ sistemin çabuk 1sınması ve ünitelere daha çabuk buhar gitmesi için gereklidir.

\section{Hava kompresörleri}

Kompresör odasinda 5 adet su soğutmalı hava kompresörü bulunmaktadır. 2 adet ZR-160, 2 adet ZR-90, 1 adet ZR-55 marka kompresördür. Tüm kompresörlerde değişken hiz sürücüsü bulunmaktadır. Kompresörler su soğutmalı olduklarından 2 adet soğutma kulesi bulunmaktadır ve 2 adet 15 kW'llk sirkülasyon pompası 
bulunmaktadır. Sistemde, su sicaklık sensörü bulunmaktadır. Suyun sicaklığına göre pompalar devreye girip çıkmaktadır. Yapılan gözlemde kule 10 dakikada 5 sefer devreye girip çıkmıştır. Bu hem motorun verimi açısından olumsuzdur hem de pompa için zararlıdır. Bu nedenle su sicaklık aralığını yeniden ayarlanması gerekmektedir.

Sisteme verilen hava sicaklığının $46{ }^{\circ} \mathrm{C}$ olması enerji tüketiminin yüksek olduğunu göstermektedir. $\mathrm{Bu}$ durum emiş havasının sıcaklığının, her $5{ }^{\circ} \mathrm{C}$ artışında \%2 verim kaybına neden olmaktadır. Ancak sistemde iklimlendirme yapıldığından ortam sıcaklığının $40-45{ }^{\circ} \mathrm{C}$ 'lere kadar çıkması tahmin edilmemektedir. Ancak tüm kompresörlerin aynı anda çalışması olasılığı da göz önünde bulundurulmalıdır. Aşağıda ortam sıcaklığının yükselmesi durumunda oluşacak tasarrufu gösteren bir hesap verilmiştir (Sapmaz ve Kaya, 2017.). Tasarruf için

Tasarruf $=$ GDO $\times$ Nominal güç $\times \mathrm{CS} \times \mathrm{YK} / \eta_{\text {motor }}$

Burada CS yıllık çalışma süresini (saat), YK yük katsayısını (\%), $\eta_{\text {motor }}$ motor verimini (\%) ve Denklem (2)'de verildiği gibi GDO ise güç düşüm oranını (\%) ifade etmektedir (Sapmaz ve Kaya, 2017).

$\mathrm{GDO}=1-\left[\left(\mathrm{T}_{\mathrm{d}}+273\right) /\left(\mathrm{T}_{\mathrm{i}}+273\right)\right]$

Burada $T_{i}$ ve $T_{d}$ sırasıyla mevcut emiş havası sıcaklığ $1\left({ }^{\circ} \mathrm{C}\right)$ ve istenen emiş havası sıcaklığ $\left({ }^{\circ} \mathrm{C}\right)$ 'dır. İstenen sicaklık genelde $21{ }^{\circ} \mathrm{C}$ civarında olmalıdır. Böylece

$\mathrm{GDO}=1-[(21+273) /(43+273)]=0,080$

olur. Kompresörün 165 kW'lık motor gücü, 7440 saatlik çalışma süresi, \%90,6'lık motor verimi, 30 ${ }^{\circ} \mathrm{C}$ ve $21{ }^{\circ} \mathrm{C}$ 'lik sırasıyla emiş ve istenen hava sıcaklıklarında 1 aylık talebi aşağıdaki gibi hesaplayabiliriz:

$$
\begin{aligned}
& 1 \text { Aylık Talep }=\text { Güç } \times \text { GDO } / \text { Verim } \\
& =22 \mathrm{~kW} \times \frac{0,080}{0,906}=1,96 \mathrm{~kW}
\end{aligned}
$$

Tüketim Tasarrufu $=1,96 \mathrm{~kW} \times 7440 \mathrm{~h} \times 0,89$ $=12278 \mathrm{kWh}$

Ekonomik Değeri $=12278 \mathrm{kWh} \times 0,40=4911,2 \mathrm{TL}$

Şekil 6'da görüldüğü gibi giriş sıcaklığı $40{ }^{\circ} \mathrm{C}$ olan hava kompresöründe oluşan su miktarı $52 \mathrm{gr} / \mathrm{m}^{3}$ olduğu görülmektedir. Kompresör hava debisi 12,68 $\mathrm{m}^{3} / \mathrm{dk}$ olduğuna göre, basınçlı havadaki su miktarı

$$
=52 \mathrm{gr} / \mathrm{m}^{3} \times 12,68 \mathrm{~m}^{3} / \mathrm{dk}=659,36 \mathrm{gr} / \mathrm{dk}
$$

olur. Emiş hava sıcaklığ $25{ }^{\circ} \mathrm{C}$ olduğunda basınçlı havadaki su miktarı ise

$$
=25 \mathrm{gr} / \mathrm{m}^{3} \times 12,68 \mathrm{~m}^{3} / \mathrm{dk}=317 \mathrm{gr} / \mathrm{dk}
$$

olur. Gözlendiği üzere giriş hava sıcaklığının düşük olması üretilen havanın içerisinde bulunan suyun miktarı ile doğru orantılıdır. Hava giriş sıcaklığının düşük olması, kompresör verimini arttırır. Havanın içerisindeki su tamamen alınmaz ise sisteme zarar verir, üretim makinalarında arıza ve korozyona neden olur. Bu durum, su traplarla ve kurutucuların iyi seçilmesi ile önlenebilir.

Tesiste 8 adet düşük basınçlı ve 7 adet yüksek basınçlı vidalı amonyak kompresörü bulunmaktadır. Ayrıca dört adet kondenser bulunmaktadır. 2 tanesi hava soğutmalı, 3 tanesi ise su soğutmalıdır. Tüm kondanserler evaporatif tiptir. Amonyak kompresörlerinde kullanılan amonyağın, gaz fazından sıvı faza geçmesi prosesi için kullanılmaktadırlar. Kondenselerde 1 motor, 3 adet fan bulunmaktadır. İçerindeki sıcak havayı alınıp, dışarı atılmaktadır. Pompa vasıtasıyla su yukarıdan basılıyor, damlacıklar halinde aşağı akarken, fanlar vasıtasıyla sudaki 1sı emilerek dışarı atılmaktadır.

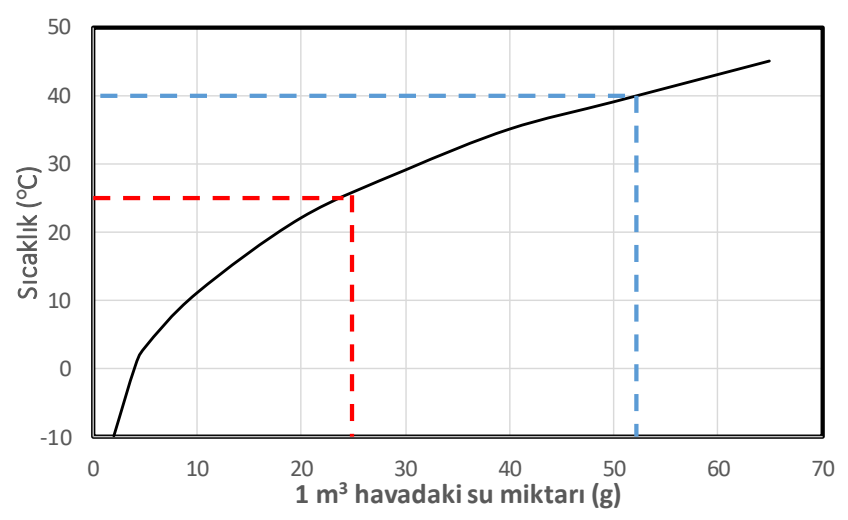

Şekil 6. Hava kompresöründeki sıcaklığa göre havadaki su miktarı eğrisi

\section{Elektrik}

Tesiste 4 adet $2000 \quad$ kVA'llk $^{\prime}$ trafo bulunmaktadır. 4 adet trafo yükte bulunmaktadır. 
Her bir trafoda enerji analizörü ile ölçüm yapılmıștır (Kaşıkçı, 2013). Her bir Trafo-1, Trafo-2, Trafo-3 ve Trafo-4 için 'tır. Onların sırasıyla ölçülen değerleri ise sirasiyla $409,6 \mathrm{~kW}, 1444,8 \mathrm{~kW}, 1498,5 \mathrm{~kW}$ ve 1965,3kW'tır. Elde edilen yük yüzdeleri Șekil 7'de gösterilmektedir.

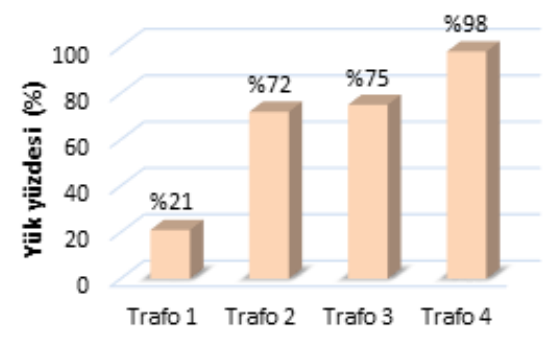

Şekil 7. Trafoların yük yüzdeler

Şekil 7'de görüldüğü gibi Trafo-4, \%100 yüke yakın çalışmaktadır. Talebin yükselmesi sonucu her an kesici açabilir. Eğer cebri soğutma yoksa \%15 tolerans edebilir. Cebri soğutma var ise bu oran \%35 'e kadar çıkabilir. Mevcut bulunan 4 trafodan 1. trafo kompanzasyonu reaktörsüz, 2. ve 3. trafoların kompanzasyonu reaktörlü, 4. trafoda da 3 adet 100 A'lik aktif reaktör bulunmaktadır. Yapılan etüt çalışmalarında tesis tam kapasite çalışmakta ve 3 . trafonunda kublajda çalıştığ 1 tespit edilmiştir. 1 . trafonun kompanzasyonunun reaktörsüz olmasından dolayı bu trafonun diğer trafolar ile kublajda çalışması harrnonik açısından sakıncalıdır. $\mathrm{Bu}$ trafonun da reaktörlü kompanzasyon sistemine geçirilmesi gerekmektedir. Gerilim harmonikleri \%5-6 aralığında ve akım harmonikleri de \%15-17 aralığındadır. $\mathrm{Bu}$ değerlerde tehlike arz edecek boyutlarda değildir.

\section{Verimlilik Arttırıcı Projeler}

Tesiste yapılan enerji etüdü ile tesisin enerji tüketimi ve kullanımlarındaki durumu değerlendirilmiş, eksiklikler, yanlış uygulamalar ve alınmas1 gereken tedbirler, yapılamas1 gereken iyileştirmeler öneriler ile sunulmuştur. Bu önerilere ek olarak önemli enerji kayıplarının özellikle buhar ve kondens hatlarında, basınçlı hava dağıtımında (Kaya, 2012) ve transformatörlerde yoğunlaştığ görülmüştür.

En önemli enerji kaybı hindistan cevizi yağının depolandığ1 tankındadır. Burada DN25 bir vanadan geçen 3,5 bar-g basınçtaki buharın, yılın soğuk olan 6 aylık kısmında 4000 saat çalışıldığ 1 düşünülürse ve giriş tarafindaki vananın tam açık olmadığı durumda dahi israf olan buharın miktar1 800 ton/y1l ve elektrik birimi olarak karş1lığ 558240 kWh/yıl'dır. Diğer bir önemli enerji kaybı transformatörlerde yaşanmaktadır. Yapılan ölçümler ile bir nolu transformatörün çok düşük yükte çalıştığ 1 fark edilmiştir. Transformatörün, \%79'u boşta olduğundan \%2-3 civarında elektrik enerjisi kayıp enerji olarak harcanmaktadır. \%2 olarak boşa harcanan yıllık enerji miktarı $295800 \mathrm{kWh} / \mathrm{y}$ 1l'dır.

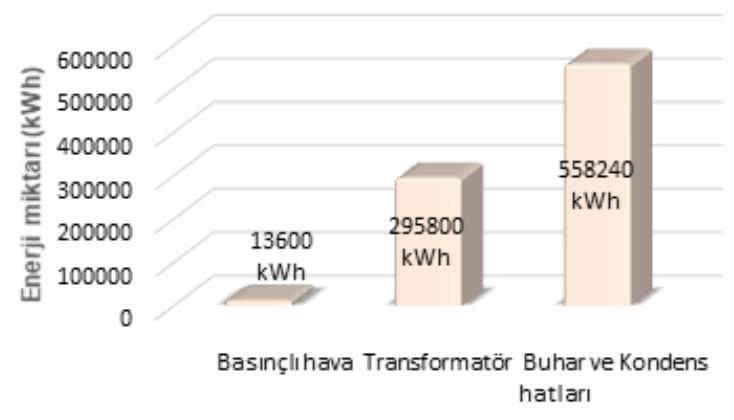

Şekil 8. Tesis için yıllık sağlanacak enerji kazançları

Arıtma tesisinde kullanılan basınçlı hava için, merkezde yer alan kompresör odasından uzun bir borulama yapıldı ̆̆ 1 görülmüştür. Buda hat kayıplarına neden olmaktadır. $\mathrm{Bu}$ nedenle daha küçük hacimli bir kompresörün konulması ile bu problem ortadan kaldırılabilir. Şu anki uygulama ile yaşanan enerji kayb1 anma çap1 $50 \mathrm{~mm}$ olan boruda kaybolan basınç 0,65 bar, elektrik karşılığ 1 ise 3,4 kW'dır. Yıllık toplam 3000 saat çalışma gereğine göre enerji kaybı $13600 \mathrm{kWh} / \mathrm{y} ı 1$ 'dır.

Tesisin yıllık sağlayacağı enerji kazançları Şekil 8'de verilmiştir. Şekil 8'den tesiste yılda ortalama 800 ton buhar (elektriksel karşıllı̆ 1558240 $\mathrm{kWh} / \mathrm{y} 11$ ), basınçlı hava sistemindeki yanlış strateji ve yaşanan kayıplar ile $13600 \mathrm{kWh} / \mathrm{y} 1 \mathrm{l}$ ve bir nolu transformatördeki düşük yük faktörü nedeni ile $295800 \mathrm{kWh} / \mathrm{y} 1 \mathrm{l}$ enerjinin kayı edildiği hesaplanmıştır. Bahsedilen üç önemli bölümde enerji verimliliği ile yapılacak iyileştirmeler ile tesiste yılda $929555 \mathrm{~kW}$ yani 80 TEP'lik bir tasarruf sağlanabilir.

Buhar ve kondens hatlarında yapılacak müdahaleler ile y1lda $558240 \mathrm{kWh}$ tasarrufun ekonomik değeri 2019 y1lı için 248062,00 TL'dir. Basınçlı hava dağıtım stratejisinde $13600 \mathrm{kWh}$ 'lik tasarruf ile 5440,00 TL ekonomi değer elde edilir. Düşük yük faktörü ile orantısız yüklenen 
transformatörlerin doğru yük yönetimi ile 295800 kWh'lik enerji kaybının önüne geçilecektir ve bunun ekonomik değeri 118320,00 TL olmaktadır. Buhar hatları, basınçlı hava dağıtım sistemi ve elektrik dağıtım sisteminde, çok düşük maliyetler ile yapılacak müdahalelerle enerjinin verimli kullanılması noktasinda toplamda $929555 \mathrm{kWh}$ ile y1lda ortalama 371822,00 TL bir tasarruf sağlanmış olunur.

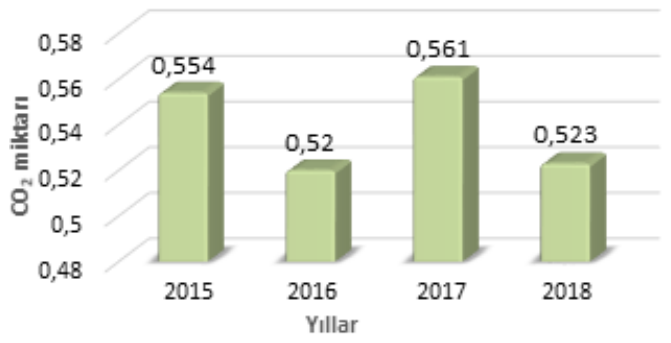

Şekil 9. Tesisin 2015-2018 yılları arasındaki ürettikleri ton ürün başına $\mathrm{CO}_{2}$ miktarı

Ayrıca tesisin son dört yıla ait ürün miktarı başına $\mathrm{CO}_{2}$ salınımı Şekil 9'da verilmiştir. Verimlilik arttırıcı projelerin bir amacı da $\mathrm{CO}_{2}$ salınımını azaltılmasıdır. Yukarıda bahsedilen verim arttırıcı projeler ile y1lda ortalama $2401547 \mathrm{~kW}$ yani yaklaşık 2,4 GW tasarruf sağlanır. Bu oranda bir tasarruf ile tesisin karbon ayak izi önemli ölçüde azaltılarak y1lda ortalama $1200733 \quad \mathrm{~kg} \quad \mathrm{CO}_{2}$ salınımının önüne geçilmiş olunur.

\section{SONUÇ}

$\mathrm{Bu}$ çalışmada ISO 50001 Enerji Yönetim Sistemi (EnYS) tanıtılmış ve yıllık 4.735 TEP enerji tüketimine sahip gida sektöründeki dondurma üretimim yapan büyük ölçekli bir tesisin enerji verimliliğini belirlemek için uygulanmıştır. EnYS etüdü ile enerji verimliliği, enerji kullanımı ve tüketiminde mevcut durum tespit edilmiş, enerji tasarrufu konusunda yapılabilecek iyileștirmeler, alınacak önlemler, verimlilik arttırıcı uygulama ve projeler araştırılmıştır. Yapılan ön etüt çalışmasında kısa vadede geri dönüşlerin alınabileceği üç nokta tespit edilmiş ve ilk etapta bu alanlara yönelik çalışmaların yapılması önerilmiştir. Bu alanlar ise buhar hatlarındaki kaçaklar ile basınçlı hava dağıtımındaki izlenen yanlış stratejiler ve dengesiz olarak yüklenen transformatörlerdir. Buhar kaçakları ile yllda $620155 \mathrm{kWh}$ değerinde 800 ton buhar kaçağının olduğu tespit edilmiştir. Alınacak basit önlemler ile y1lda 54 TEP ve 248062 TL ekonomik değerindeki buhar kaçakları önlenebilir. İkinci olarak, yapılan ölçümler ile tesisteki dört dağıtım transformatöründe dengeli bir şekilde yük dağılımının yapılmadığı ve dolayısıyla trafonun bir tanesinde (Trafo-1) düşük yük faktörü ile \%2-3 oranıla yılda $295800 \quad \mathrm{~kW}$ enerji kayb1 yaşanmaktadır. Atık arıtma merkezinin ihtiyacı olan basınçlı hava, merkezi kompresör odasından sağlanmaktadır. Kompresör odası ile atık arıtma tesisi arasındaki mesafenin fazla olması sebebiyle her 100 metrede 6,5 bar basınç düşümüne karşılık $3,4 \mathrm{~kW}$ enerji kaybı yaşanmaktadır ve yılda 13600 $\mathrm{kWh}$ enerji israf olmaktadır. Bu üç verimlilik arttırıcı uygulama ve projeler ile yılda $1 \mathrm{GW}$ 'a yakın enerji tasarrufu sağlanabilir. Buna karşıllk tesisin karbon ayak izini azaltma çalışmalarına yardımcı olarak yılda $1200733 \mathrm{~kg} \mathrm{CO}$ salınımı engellenmiş olacaktır. Tesisin y1llık 4735 TEP enerji tükettiği dikkate alınırsa yıllık 473 TEP'lik bir tasarruf söz konusudur.

\section{ÇIKAR ÇATIŞMASI BEYANI}

Yazarlar bu çalışmasında herhangi bir şekilde çıkar çatışması olmadığını beyan eder.

\section{ARAŞTIRMA VE YAYIN ETİĞİ BEYANI}

Yazarlar bu çalışmasında araştırma ve yayın etiğine uyulduğunu beyan eder.

\section{REFERANSLAR}

Aksoy, S., Çalıkoğlu, E., Aras, H., Karakoç, N., 2013. Enerji yönetimi ve politikaları. Anadolu Üniversitesi Yayınları, Eskişehir.

Christoffersen, L.B., Larsen, A., Togeby, M., 2006. Empirical analysis of energy management in Danish industry. Journal of Cleaner Production, 14(5):516-526.

Corsini, A., Bonacina, F., Feudo, S., Lucchetta, F., Marchegiani, A., 2016. Multivariate KPI for energy management of cooling systems in food industry. Energy Procedia, 101:297-304.

EMO, 2011. Enerji Raporu. Elektrik Mühendisleri Odası, İzmir.

ETKB YEGM, 2018. 2010-2016 Türkiye enerji verimliliği gelişim raporu. Enerji Verimliliği Dairesi Başkanlığı Ölçme ve Değerlendirme Grubu, EV-2018-01-V1, Ankara.

Ferland, K., Brown, J., Bill Meffert, B., Hake, D., Krawczyk, M., Mazza, M., Waz, P., 2009. Results from the Texas pilot project on manufacturing plant energy efficiency certification. In: ACEEE 
summer study on energy efficiency in industry; 2009. 42-53.

Fichera, A., Volpe R., Cutore E., 2020. Energy performance measurement, monitoring and control for buildings of public organizations: Standardized practises compliant with the ISO 50001 and ISO 50006. Developments in the Built Environment, 4:100024.

Halkbank, 2007. Sanayi ve Kobi'ler için enerji verimli rehberi. Halkbank (Turkishtime), Ankara.

Jovanovic, B., Filipovic, J., Bakic, V., 2017. Energy management system implementation in Serbian manufacturing - Plan-Do-Check-Act cycle approach. Journal of Cleaner Production, 162:1144-1156.

Kaşıkçı, İ., 2013. Elektrik Mühendisliği. Birsen Yayınevi, İstanbul.

Kaya, D., Öztürk H.H., 2014. Sanayide enerji yönetimi ve enerji verimliliği. Umuttepe Yayınları, Kocaeli.

Kaya, M., 2012. Sanayide Enerji Verimliliği Potansiyeli ve Basınçlı Hava Sistemlerinde Verimlilik. Yüksek Lisans Tezi, Yıldız Teknik Üniversitesi, İstanbul.

Mendoza, R.C., Hernandez, J.M.R., Gomez, E.V., Alonso, J.S.J., Martìnez, F.J.R., 2019. Analysis of the methodology to obtain several key indicators performance (KIP), by energy retrofitting of the actual building to the district heating fuelled by biomass, focusing on nZEB goal: case of study. Energies, 12:93.

Mezinska, I., Strode, S., 2015. Emerging horizons of environmental management in food sector companies. Procedia - Social and Behavioral Sciences, 213:527-532.

Paker, A.S., 2019. Bir endüstri tesisinde, enerji risk analiz ve yönetimi: ISO 50001 bakışıyla bir çalışma örneği. Tesisat Mühendisliği, 26(129): 64-70.

Papar, R., Harrell, G., Venkatesan, V., 2017. Endüstriyel sistemlerde optimizasyon/buhar sistemleri. Birleşmiş Milletler Sınai Kalkınma Teşkilatı (UNIDO), YEGM, İstanbul.

Pekaçar, M., 2011. ISO 50001 Enerji Yönetim Sistemi. II. Elektrik Tesisat Ulusal Kongresi, 24-27 Kasım 2011, İzmir

Pelser, W.A., Vosloo, J.C., Mathews, M.J., 2018. Results and prospects of applying an ISO 50001 based reporting system on a cement plant. Journal of Cleaner Production, 198:642-653.

Polat, B., Bayram, N., Polat, A., 2017. Güneydoğu Anadolu Bölgesi için İnşaat Sektöründeki İş Güvenliği Koşullarının İncelenmesi. International Journal of Pure and Applied Sciences, 3(2):68-78.

Ruşen, S.E., Çevik, M.S., 2020. Bir gıda fabrikasında enerji verimliliğinin iyileştirilmesi. Süleyman Demirel Üniversitesi Fen Bilimleri Enstitüsü Dergisi, 24(3):539-552.
Sapmaz, S., Kaya, D., 2017. Basınçlı hava sistemlerinde enerji verimliliği ve emisyon azaltım firsatlarının incelenmesi. Mühendis ve Makine, 58(689):23-36.

Söğüt, Z., Üren, S., Çelik, C., Durmaz, Ş., Orhan İ., 2013. Sanayide Enerji Ekonomisi. Anadolu Üniversitesi Yayınları, Eskişehir.

Ural, T., Akgün, M., Ertürk, M., (2020). Türkiye'de Doğalgazın Tüketildiği Mahallerde Kullanılan Havalandirma Menfezlerin Optimizasyonu. International Journal of Pure and Applied Sciences, 6(2):157-168.

Uzun, A., Değirmen, M., 2018. Endüstriyel işletmelerde enerji verimliliği ve enerji yönetimi. Uluslararası Ekonomik Araştırmalar Dergisi, 4(2):83-97. 